\title{
Topuk dikeni tedavisinde ekstrakorporeal şok dalga tedavisinin etkinliği
}

\section{Effectiveness of extracorporeal shock wave therapy in the treatment of epin calcanei}

iD Nihan Cüzdan¹, iD Deniz Evcik², iD Saime Ay³.

${ }^{1}$ Balıkesir Atatürk Şehir Hastanesi, Romatoloji Kliniği, Balıkesir, Türkiye

${ }^{2}$ Güven Hastanesi, Fiziksel Tıp ve Rehabilitasyon Kliniği, Ankara, Türkiye

${ }^{3}$ Ufuk Üniversitesi Tıp Fakültesi, Fiziksel Tıp ve Rehablitasyon ABD, Ankara, Türkiye

\section{$\ddot{\mathbf{O} z}$}

Amaç: Topuk dikeni klinikte sıkça karşılaşılan, kronik plantar topuk ağrısına neden olan klinik bir tablodur. Hastalara uygulanan kortikosteroid enjeksiyonu, steroid olmayan antiinflamatuvar ilaçlar ve çeşitli fizik tedavi modaliteleri gibi seçeneklerin yanında, Ekstrakorporeal Şok Dalga Tedavisi (Extracorporeal Shock Wave Therapy - ESWT) cerrahi olmayan yöntemler arasında yerini almıştır. Bu prospektif kontrollü çalısmanın amacı klinik ve radyolojik olarak topuk dikeni tanısı alan hastalarda ESWT tedavisinin etkinliğini araștırmaktır.

Gereç-Yöntem: Çalışmaya klinik ve radyolojik olarak topuk dikeni tanısı konan 49 hasta alındı. Hastalar randomize olarak iki gruba ayrıldı. Grup 1 (n=25) silikon tabanlık kullandı ve dört gün aralıkla 3 seans boyunca $8 \mathrm{~Hz}$ frekans ile her seans 1000 atım olacak şekilde ESWT tedavisi aldı. Grup 2 (n=24) ise kontrol grubu olarak kabul edildi ve sadece silikon tabanlık kullandı. Ağrı șiddeti gece ağrısı, sabah ilk basma sırasındaki ağrı, hareket ile ağrı, istirahat ağrısı, engebeli zeminde ağrı ve gün sonunda ağrı olmak üzere Görsel Analog Skala (GAS) ile ve ayak aktiviteleri ile ilgili fonksiyonel düzey ise Ayak ve Ayak Bileği Sonuç Skoru (Foot and Ankle Outcome Score - FAOS) indeksi ile değerlendirildi. Ölçümler hastalar tedaviye alınmadan önce ve 4 haftalık izlem sonrasında yapıldı.

Bulgular: Tedavi sonrasında her iki grupta tüm parametrelerde istatistiksel olarak anlamlı iyileșme saptandı $(\mathrm{p}<0.05)$. Gruplar arası değerlendirmede ise tedavi sonrasında GAS ile hesaplanan gece ağrısı ve sabah ilk basma sırasındaki ağrıda $(\mathrm{p}<0.05)$ ESWT grubu lehine olacak şekilde anlamlı düzelme olduğu gözlemlendi. Diğer parametrelerde ise tedavi sonrasında her iki grup arasında anlamlı fark bulunmadı $(\mathrm{p}>0.05)$.

Sonuç: Çalışmamızın sonuçlarına göre ESWT uygulaması topuk dikenine bağlı ağrı semptomunu azaltmada efektif bir konservatif yöntem olarak görülmektedir.

Anahtar Kelimeler: ESWT, epin kalkanei, plantar ağr1

\begin{abstract}
Objective: Epin calcanei is a common clinical problem with chronic plantar heel pain. 'Extracorporeal Shock Wave Therapy (ESWT)' is a non-surgical method administered to patients along with a variety of other options such as corticosteroid injections, non-steroidal antiinflammatory drugs and physical therapy modalities. The aim of this prospective controlled study is to investigate the efficacy of ESWT in patients with clinical and radiological diagnosis of epin calcanei.

Materials-Methods: The study included 49 patients diagnosed with epin calcanei according to the clinical and radiological criteria. Patients were randomly divided into two groups. Group $1(\mathrm{n}=25)$ used silicone insoles and received ESWT treatment as 1000 shots in each session at a frequency of $8 \mathrm{~Hz}, 3 \mathrm{sessions}$ in total with intervals of four days. Group $2(\mathrm{n}=24)$ was accepted as the control group and used silicone insoles alone. The severity of pain was evaluated using the pain Visual Analog Scale (VAS) as pain at night, pain in the morning, on the first step, pain on motion, pain at rest, pain on uneven ground and pain at the end of the day. The functional level of activity of the foot was evaluated by the Foot and Ankle Outcome Score (FAOS) index. Measurements were taken before
\end{abstract} treatment and after 4 weeks of follow-up.

Results: After treatment, both groups showed statistically significant improvement in all parameters $(\mathrm{p}<0.05)$. Post-treatment VAS scores showed significant improvements in pain at night and pain in the morning on the first step $(\mathrm{p}<0.05)$ in ESWT group. However there was no significant difference in other parameters between the two groups $(\mathrm{p}>0.05)$.

Conclusion: According to the results of our study, ESWT application is seen as an effective conservative method in decreasing pain related to heel spur.

Keywords: ESWT, Epin calcanei, plantar pain

Yazışma Adresi: Nihan Cüzdan, Balıkesir Atatürk Şehir Hastanesi, Romatoloji Polikliniği, G Blok 1. Kat, Altıeylül, Balıkesir, Türkiye

E-Posta: nihancuzdan@hotmail.com

Alınma Tarihi: 13.11.2019 / Kabul Tarihi: 09.09.2020 / Yayımlanma Tarihi: 15.06.2021

Topuk dikeninde ESWT - Cüzdan ve ark. 
Topuk ağrısı toplumda sık karşılaşılan, popülasyonun \%10 kadarında görülebilen ve kişinin günlük yaşamını etkileyebilen bir durumdur (1). Ağrının temelinde, çeşitli etiyolojik nedenler bulunabilir. Topuk ağrıs1, ağrının lokalizasyonuna göre plantar, medial, lateral ve posterior olarak sınıflandırılabilir (2). Topuk dikeni, kronik plantar topuk ağrısına neden olan klinik bir tablodur (3). Genellikle 40-50 yaş arasında kadınlarda görülmektedir (4). Obezitede görülme sıklığ 1 artmıştır (5). Topuk dikeninin patolojisinde, predispozan faktörlerin etkisiyle plantar fasyanın kronik mikrotravmalara maruz kalması sonras1 inflamasyonu ve bu inflamasyon sonrası plantar fasya proksimalinde kalsifikasyonu yer almaktadır (6). Hastalar genellikle sabah ilk basma sırasında oluşan şiddetli ağrı tariflemektedirler (7). Tedavisinde konservatif, medikal ve cerrahi yöntemler mevcuttur. Konservatif tedavi yöntemleri arasında ortez kulanımı, kortikosteroid enjeksiyonu, kinezyoterapi, iyontoforez, lazer, ultrason, mikrodalga, fonoforez ve son zamanlarda artmış kullanımı olan ekstrakorporal şok dalga tedavisi (Extracorporeal Shock Wave Therapy: ESWT)'dir (8).

ESWT, plantar fasiitis, medial ve lateral epikondilit, tendinopatiler ve topuk dikeninde kullanılan invaziv olmayan bir yöntemdir. Yüksek amplitüdlü ses dalgalarının vücudun istenen bölgesine odaklanması ve orada tedavi sağlaması esasına dayalı olarak cerrahi olmayan yöntemler arasında yerini almıştır. Amerikan gıda ve ilaç bürosu (U.S. Food and Drug Administration; FDA), kronik proksimal plantar fasiitte ESWT uygulamasını 2000 yılında onaylamıştır (9). ESWT tedavisinin etkinliği konusunda yapılan çalışmaların sonuçları çelişkilidir (10-14). Bir metaanalizde özellikle semptomatik açıdan iyileştirici etkinliği nedeni ile cerrahi yöntemlerden önce göz önüne alınması gerektiği savunulmuştur (15).

$\mathrm{Bu}$ prospektif randomize kontrollü çalışmanın amacı klinik ve radyolojik olarak topuk dikeni tanısı alan hastalarda ESWT tedavisinin ağrı ve fonksiyon üzerine etkinliğinin araştırılmasıdır.

\section{Yöntem}

\section{Hasta grupları}

Çalışmaya hastanemiz Fizik Tedavi ve Rehabilitasyon polikliniğine 2012-2013 yılları arasında başvuran 18-70 yaş arası, 3 aydan uzun süreli topuk ağrısı mevcut olan, klinik ve radyolojik olarak topuk dikeni tanısı almış olan hastalar alındı. Takibe gelemeyecek olanlar, 18 yaş altı hastalar, romatoid artrit ve diğer romatolojik hastalıklara sahip olanlar, koagulasyon bozukluklarına sahip olanlar, kalkaneal stres kırığı olanlar, gebe ve emziren hastalar çalışma dışı bırakıldı. Çalışma protokolü hastanemiz etik kurulu tarafından onaylandı. Çalışma Helsinki Deklarasyonu ilkelerine uygun olarak gerçekleştirildi. Tüm hastalardan bilgilendirilmiş onam formları alındı. Hastaların ilk poliklinik başvurusu sırasında klinik ve demografik özellikleri kaydedildi.

Hastalar kapalı zarf metodu ile randomize edilerek iki gruba ayrıldılar. Grup $1(\mathrm{n}=25)$; silikon tabanlık kullandı ve dört gün aralıkla 3 seans boyunca $8 \mathrm{~Hz}$ frekans ile her seans 1000 atım olacak şekilde ESWT tedavisi ald1. Grup 2 ( $\mathrm{n}=25)$; ise kontrol grubu olarak kabul edildi ve sadece silikon tabanlık kullandı. Silikon tabanlığın ESWT hastanın çalışmaya dahil edilmesinden son değerlendirme gününe kadar kullanılması istendi. ESWT tedavisi bu konuda eğitim almış bir fizyoterapist tarafından uygulandı. Tedavi öncesi ve sonrası değerlendirmeler tek araştırmacı tarafından yapıldı. Değerlendirmeleri yapan araştırmacı tedavi grupları yönünden kördü.
Tedavide EMS Swiss DolorClast (EMS Electro Medical Systems; Dallas, TX, USA) cihazı kullanıldı. Tedavi grubundaki hastalara ayak bilek eklemi nötral pozisyonda olacak şekilde yüzüstü pozisyon verildi. ESWT uygulaması hastaların kalkaneus medialinde tespit edilen en hassas noktaya yapıldı. Hastaların kronik ağrı düzeyine etki edebilecek (pregabalin, gabapentin, opioid, steroid vb) mevcut tedavilerinin devamı önerildi. Çalışma süresince ağrıya yönelik ek tedavi alınmaması (parasetamol, steroid olmayan anti-inflamatuvar, opiod ve antiepileptikler) ve topuk bölgesine ek tedavi uygulanmamas1 istendi.

\section{Klinik değerlendirme}

Ağrı şiddeti; gece ağrısı, sabah ilk basma sırasındaki ağrı, hareket ile ağr1, istirahat ağrıs1, engebeli zeminde ağr1 ve gün sonunda ağr1 olmak üzere Görsel Analog Skala (GAS) ile değerlendirildi. GAS; başlangıcı ' $0=$ ağrı yok” ve diğer ucu ' $10=$ ç̧ok şiddetli ağrı var' ibareleri olan ve birer santimetre $(\mathrm{cm})$ aralarla her cm'ye rakamsal değer verilen bir skaladır (16). Hastalardan bu çizgi üzerinde kendi ağrı durumlarına uygun olan yere işaret koyması istendi.

Ayak aktiviteleri ile ilgili fonksiyonel düzey ise Ayak ve Ayak Bileği Sonuç Skoru (Foot and Ankle Outcome Score - FAOS) indeksi ile değerlendirildi. FAOS skorlaması Knee Injury and Osteoarthritis Outcome Score baz alınarak yapılımış ve ayak bilek instabilitesi olan 213 hastada validasyonu onaylanmış bir fonksiyonel düzey skorlama sistemidir (17). Ağrı, belirti, iş, günlük yaşam, spor ve yaşam kalitesi alt skalaları mevcuttur. Her soru Likert ölçeği ile 0-4 arasında skorlanır. Her alt skala toplamda 0 (semptomları en şiddetli) ve 100 (semptom yok) arasında skorlanmaktadır. Anketin geçerli Türkçe versiyonu mevcuttur (18).

Ölçümler hastalar tedaviye alınmadan önce ve 4 haftalık izlem sonrasında olmak üzere toplam iki kere yapıldı.

\section{İstatistiksel değerlendirme}

İstatiksel analizlerde Windows için IBM SPSS 17.0 versiyon istatistik paketi kullanıldı. Sayısal değişkenler ortalama \pm standart sapma ile nitelik değişkenler ise sayı ve yüzde ile gösterildi. Grup içi tedavi öncesi ve tedavi sonrası karşılaştırmaları için Wilcoxon testi kullanıldı. Bağımsız gruplarda gruplar arasında sayısal değişkenler bakımından farklılık olup olmadığına Mann Whitney $U$ testi ile bakıldı. 0.05 değerinin altındaki p değerleri istatistiksel olarak anlamlı kabul edildi.

\section{Bulgular}

Çalı̧̧maya toplam 50 hasta alındı. Kontrol grubundaki 1 hastanın takibi bırakması sebebi ile istatistiksel değerlendirmeye 41'i kadın 8'i erkek toplam 49 hasta dahil edildi. Hastaların yaş ortalaması grup 1'de $50.0 \pm 10.8$ ve grup 2 de $57.7 \pm 11.2$ yıld 1 ( $\mathrm{p}=0.006)$. Gruplar arasında cinsiyet, boy-kilo oranı ve semptom süresi ortalaması açısından anlamlı farklılı saptanmadı $(\mathrm{p}>0.05)$. Hastaların demografik özellikleri tablo 1'de gösterilmiştir (tablo 1).

Tedavi öncesi ve tedavi sonrası 4. haftada değerlendirilmiş tüm ağnı parametrelerinde (gece ağrısı, sabah ilk basma sırasındaki ağr1, hareket ile ağr1, istirahat ağrıs1, engebeli zeminde ağr1 ve gün sonunda ağrı) her iki grupta da istatistiksel olarak anlamlı iyileşme saptand $1(\mathrm{p}<0.05)$ (tablo 2). Gruplar arasındaki değerlendirmede ise tedavi sonrasında GAS ile hesaplanan gece ağrısı ve sabah ilk basma sırasındaki ağrı, ESWT grubu lehine olacak şekilde anlamlı düzelme olduğu gözlemlendi $(\mathrm{p}<0.05)$ (tablo 3$)$.

Topuk dikeninde ESWT - Cüzdan ve ark. 
Tablo 1. Hastaların sosyodemografik özellikleri

\begin{tabular}{|c|c|c|c|c|}
\hline & & Grup 1 & Grup 2 & $\mathrm{p}$ \\
\hline \multicolumn{2}{|c|}{ Yaş (yıl) (ort $\pm \mathrm{SS}$ ) } & $50.00 \pm 10.87$ & $57.79 \pm 11.27$ & $0.006^{* *}$ \\
\hline \multirow{2}{*}{ Cinsiyet n (\%) } & Kadın & $19(76)$ & $22(91.7)$ & \multirow{2}{*}{0.142} \\
\hline & Erkek & $6(24)$ & $2(8.3)$ & \\
\hline \multicolumn{2}{|l|}{$\mathrm{VKI}\left(\mathrm{kg} / \mathrm{m}^{2}\right)$} & $30.6 \pm 1.3$ & $30.0 \pm 1.2$ & 0.734 \\
\hline \multirow{4}{*}{$\begin{array}{l}\text { Eğitim durumu } \\
\mathrm{n}(\%)\end{array}$} & Okur-yazar değil & $3(12)$ & $3(12.5)$ & \multirow{4}{*}{0.236} \\
\hline & İlköğretim & $11(44)$ & $9(37.5)$ & \\
\hline & Lise & $8(32)$ & $7(29.2)$ & \\
\hline & Üniversite & $3(12)$ & $5(20.8)$ & \\
\hline \multirow{3}{*}{$\begin{array}{l}\text { Meslek durumu } \\
\mathrm{n}(\%)\end{array}$} & Memur & $5(20)$ & $4(16.7)$ & \multirow{3}{*}{0.617} \\
\hline & Özel sektör & $5(20)$ & $2(8.3)$ & \\
\hline & Çalıșmıyor & $15(60)$ & $18(75.0)$ & \\
\hline
\end{tabular}

Ort: ortalama, SS: standart sapma, n: number,

Tablo 2. Tedavi öncesi ve sonrası ağrı ve fonksiyon değerlerinin grup içi karşılaştırması

\begin{tabular}{|c|c|c|c|c|c|c|}
\hline & \multicolumn{3}{|c|}{ Grup 1} & \multicolumn{3}{|c|}{ Grup 2} \\
\hline & $\begin{array}{l}\text { Tedavi } \\
\text { öncesi }\end{array}$ & $\begin{array}{l}\text { Tedavi } \\
\text { sonrasi }\end{array}$ & $\mathrm{p}$ & $\begin{array}{l}\text { Tedavi } \\
\text { öncesi }\end{array}$ & $\begin{array}{l}\text { Tedavi } \\
\text { sonrasi }\end{array}$ & $\mathrm{p}$ \\
\hline $\begin{array}{l}\text { Gece ağrisı (ort } \\
\quad \pm \text { SS) }\end{array}$ & $\begin{array}{c}6.08 \pm \\
3.21\end{array}$ & $\begin{array}{l}2.76 \pm \\
2.50\end{array}$ & $<0.001$ & $\begin{array}{c}4.91 \pm \\
2.26\end{array}$ & $4.08 \pm 2.06$ & $<0.001$ \\
\hline $\begin{array}{c}\text { Sabah ilk basma } \\
\text { ağrı (ort } \pm S S \text { ) }\end{array}$ & $\begin{array}{l}7.84 \pm \\
2.09\end{array}$ & $\begin{array}{c}4.44 \pm \\
2.58\end{array}$ & $<0.001$ & $\begin{array}{c}7.16 \pm \\
2.05\end{array}$ & $5.87 \pm 1.94$ & 0.001 \\
\hline $\begin{array}{l}\text { Hareket ağris1 } \\
\text { (ort } \pm \text { SS) }\end{array}$ & $\begin{array}{l}6.64 \pm \\
2.59\end{array}$ & $\begin{array}{c}4.04 \pm \\
2.38\end{array}$ & $<0.001$ & $\begin{array}{c}5.33 \pm \\
2.31\end{array}$ & $4.37 \pm 2.01$ & 0.004 \\
\hline $\begin{array}{l}\text { İstirahat ağrisı } \\
\text { (ort } \pm \mathrm{SS} \text { ) }\end{array}$ & $\begin{array}{c}4.96 \pm \\
2.96\end{array}$ & $\begin{array}{l}2.56 \pm \\
2.23\end{array}$ & $<0.001$ & $\begin{array}{c}3.45 \pm \\
2.39\end{array}$ & $2.91 \pm 2.20$ & 0.034 \\
\hline $\begin{array}{l}\text { Engebeli zemin } \\
\text { ağn1 (ort } \pm \text { SS) }\end{array}$ & $\begin{array}{l}7.52 \pm \\
2.55\end{array}$ & $\begin{array}{c}5.16 \pm \\
2.52\end{array}$ & $<0.001$ & $\begin{array}{c}6.04 \pm \\
2.27\end{array}$ & $5.00 \pm 1.84$ & $<0.001$ \\
\hline $\begin{array}{l}\text { Gün sonu ağrn } \\
\text { (ort } \pm \mathrm{SS} \text { ) }\end{array}$ & $\begin{array}{l}8.00 \pm \\
2.44\end{array}$ & $\begin{array}{c}4.80 \pm \\
2.29\end{array}$ & $<0.001$ & $\begin{array}{c}7.00 \pm \\
2.14\end{array}$ & $5.75 \pm 1.98$ & $<0.001$ \\
\hline $\begin{array}{l}\text { FAOS belirti skor } \\
\quad \text { (ort } \pm \text { SS) }\end{array}$ & $\begin{array}{c}42.00 \pm \\
15.91\end{array}$ & $\begin{array}{c}56.14 \pm \\
12.69\end{array}$ & $<0.001$ & $\begin{array}{c}47.19 \pm \\
13.75\end{array}$ & $\begin{array}{c}53.27 \pm \\
14.51\end{array}$ & $<0.001$ \\
\hline $\begin{array}{l}\text { FAOS ağrn skor } \\
\text { (ort } \pm \text { SS) }\end{array}$ & $\begin{array}{c}38.44 \pm \\
13.36\end{array}$ & $\begin{array}{c}62.22 \pm \\
17.47\end{array}$ & $<0.001$ & $\begin{array}{c}51.62 \pm \\
18.09\end{array}$ & $\begin{array}{c}58.21 \pm \\
17.99\end{array}$ & 0.006 \\
\hline $\begin{array}{l}\text { FAOS is, ADL } \\
\text { skor (ort } \pm \text { SS) }\end{array}$ & $\begin{array}{c}41.17 \pm \\
17.74\end{array}$ & $\begin{array}{c}67.82 \pm \\
14.54\end{array}$ & $<0.001$ & $\begin{array}{c}53.67 \pm \\
17.20\end{array}$ & $\begin{array}{c}62.12 \pm \\
16.50\end{array}$ & 0.002 \\
\hline $\begin{array}{l}\text { FAOS is,spor } \\
\text { skor (ort } \pm \text { SS) }\end{array}$ & $\begin{array}{c}27.20 \pm \\
20.21\end{array}$ & $\begin{array}{c}54.20 \pm \\
23.03\end{array}$ & $<0.001$ & $\begin{array}{c}46.87 \pm \\
20.68\end{array}$ & $\begin{array}{c}56.45 \pm \\
19.91\end{array}$ & 0.001 \\
\hline $\begin{array}{l}\text { FAOS yaşam } \\
\text { kalitesi skor (ort } \\
\pm \mathrm{SS} \text { ) }\end{array}$ & $\begin{array}{c}22.00 \pm \\
15.42\end{array}$ & $\begin{array}{c}47.75 \pm \\
23.02\end{array}$ & $<0.001$ & $\begin{array}{c}40.72 \pm \\
23.30\end{array}$ & $\begin{array}{c}53.90 \pm \\
18.59\end{array}$ & $<0.001$ \\
\hline
\end{tabular}

Ort:ortalama, SS: standart sapma, FAOS: foot and ankle outcome score, $\mathrm{ADL}$ skor=iş, günlük yaşam skoru

Hastaların grup içi tedavi öncesi ve sonrası fonksiyonel değerlendirmelerinde, her iki grupta da anlamlı farkl1l1k saptandı $(p<0.05)$ (tablo 2). FAOS ile ölçülen fonksiyonel düzey değerlendirmesinde gruplar arasında anlamlı fark bulunmadı $(\mathrm{p}>0.05)$ (tablo 3).

Topuk dikeninde ESWT - Cüzdan ve ark.
Tablo 3. Tedavi sonrası ağrı ve fonksiyon ölçeklerinin gruplar arası karşılaştırmaları

\begin{tabular}{|c|c|c|c|}
\hline & Grup 1 & Grup 2 & $\mathrm{p}$ \\
\hline Gece ağrısı ort \pm (min-max) & $2.76 \pm 2.50$ & $4.08 \pm 2.06$ & $0.050^{*}$ \\
\hline Sabah ilk basma ağr1 ort \pm (min-max) & $4.44 \pm 2.58$ & $5.87 \pm 1.94$ & $0.033^{*}$ \\
\hline Hareket ağrısı ort \pm (min-max) & $4.04 \pm 2.38$ & $4.37 \pm 2.01$ & 0.599 \\
\hline İstirahat ağrısı ort \pm (min-max) & $2.56 \pm 2.23$ & $2.91 \pm 2.20$ & 0.577 \\
\hline Engebeli zemin ağrn ort \pm (min-max) & $5.16 \pm 2.52$ & $5.00 \pm 1.84$ & 0.802 \\
\hline Gün sonu ağr ort \pm (min-max) & $4.80 \pm 2.29$ & $5.75 \pm 1.98$ & 0.128 \\
\hline FAOS belirti skor (ort $\pm \mathrm{SS}$ ) & $56.14 \pm 12.69$ & $53.27 \pm 14.51$ & 0.737 \\
\hline FAOS ağr skor (ort \pm SS) & $62.22 \pm 17.47$ & $58.21 \pm 17.99$ & 0.790 \\
\hline FAOS is,ADL skor (ort $\pm \mathrm{SS}$ ) & $67.82 \pm 14.54$ & $62.12 \pm 16.50$ & 1.282 \\
\hline FAOS is,spor skor (ort $\pm \mathrm{SS}$ ) & $54.20 \pm 23.03$ & $56.45 \pm 19.91$ & 0.366 \\
\hline FAOS yaşam kalitesi skor (ort $\pm \mathrm{SS}$ ) & $47.75 \pm 23.02$ & $53.90 \pm 18.59$ & 1.027 \\
\hline
\end{tabular}

Ort:ortalama, SS: standart sapma, FAOS: foot and ankle outcome score, min: minimıum, max: maximum, $\mathrm{ADL}$ skor=iş, günlük yaşam skoru

\section{Tartışma}

Topuk dikeni ve ona eşlik edebilen plantar fasiit topuk ağrılarının en sık gözlenen nedenlerinden biridir. Topuk ağrısı ile başvuran hastaların yaklaşık \%50 kadarında topuk dikeni bulunmaktadır (19). ESWT uygulamas1, 3 aydan uzun süreli topuk ağrısı olan ve diğer konservatif tedavilere cevap vermeyen hastalarda önerilmektedir (20). Çalışmamızın sonuçlarına göre, topuk dikeni tedavisinde ESWT uygulaması ağrı semptomuna ve ayak aktiviteleri ile ilgili fonksiyonel düzey üzerine etkili bulunmuştur. Sadece silikon tabanlık uygulaması ile de benzer etkiler görülmekle beraber ESWT tedavisinin ağrı semptomunda ek iyileştirici katkısı gözlenmiştir.

ESWT'nin etki mekanizması tam olarak bilinmemektedir. Fakat, uygulandığı bölgede mikrovaskülarizasyonu bozarak neovaskülarizasyonu tetiklediği ve sonrasında lokal büyüme hormonlarının salınımı ile kök hücrelerden normal doku oluşması yolu ile iyileşmeyi hızlandırdığı hipotezi mevcuttur (21). Kas-iskelet sistemi ağrılarında kullanım alanı geniş olmakla beraber son yıllarda özellikle inatçı topuk ağrılarında etkin olduğunu gösteren çalışmalar vardir (22-24).

ESWT'nin topuk ağrısında faydalı olduğunu gösteren bir çok çalışma olmasına karşın klinik etkinliği konusunda halen çelişkiler mevcuttur. Yalçın ve ark.'nın 108 hastada topuk dikeni üzerine ESWT'nin etkinliğini incelediği bir çalışmada, ESWT tedavisi beş hafta $0.05 \mathrm{~mJ} /$ $\mathrm{mm}^{2}$ dozunda başlanıp $0.4 \mathrm{~mJ} / \mathrm{mm}^{2}$ ye yükseltilerek 2000 atım olacak şekilde uygulanmıştır. Tedavi sonrasında VAS ile ölçülen ağrıda azalma olduğu bildirilmiş fakat radyolojik iyileşme ile bir korelasyon saptanmamıştır (12). Hayta ve ark.'nın çalışmasında ise ESWT tedavisi topuk dikeni olan obez hastalara 7 gün aralıkla 120 frekans ve 1200 atım şeklinde 2 seans uygulanmış ve ağrı semptomunda anlamlı iyileşme saptanmıştır (25). Cosentino ve ark.'nın çalışmasında ESWT her seans $0.03-0.4 \mathrm{~mJ} / \mathrm{mm}^{2}$ doz, 120 frekans ve 1200 atım olacak şekilde 7-10 gün aralıkla 6 kere uygulanmış ve VAS ile ölçülen ağrıda kontrol grubuna göre anlamlı azalma görülmüştür (14). Yakın zamanda yayınlanmış başka bir çalışmada plantar fasiitte ESWT ve kişiye özel dizayn edilmiş silikon tabanlık etkisi karşılaştırılmış ve 48 haftalık takip sonunda bizim çalışmamızın sonuçlarını destekler nitelikte basma ve gece ağrısında ESWT grubunda daha belirgin iyileşme saptanmıştır (26). Uğurlar ve ark.'nın çalı̧̧masında ise kronik plantar fasiit tedavisinde ESWT, lokal kortikosteroid enjeksiyonu, proloterapi ve platelet zengin plazma uygulaması birbirleri ile karşılaştırılmış ve ESWT'nin özellikle ilk 6 ayda ağrı 
üzerine etkin olduğu görülmüştür (27). ESWT'nin topuk dikeninin eşlik etmediği kronik plantar fasitte de uzun dönemde etkin olduğunu gösteren çalışmalar mevcuttur (28-30). Literatürde, ESWT'nin ağrı üzerine çok etkili bulunmadığını gösteren çalışmalar da vardır. Bu çalışmaların çoğunun ortak özelliği, kontrol grubuna ESWT'nin etkisiz dozlarının placebo şeklinde uygulanmasıdır. Buchbinder ve ark.'nın yaptığı çalışmada kontrol grubuna daha düşük dozda daha az sayıda atım verilmiş ve orta dönem ağrı etkinliği açsından ESWT ve kontrol grupları arasında istatistiksel anlamlı fark bulunmamıştır (10). Haake ve ark.'nın çalışmasında ise yine düşük doz az atım sayısı ile ESWT tedavisi uygulanan kontrol grubu ile ESWT grubu arasında uzun dönemde ağrı ve yürüme süresi açısından anlamlı fark bulunmamıştır (11). Bizim çalışmamızın sonuçlarına göre, silikon tabanlığa ek olarak ESWT uygulanan hasta grubunda gece ağrısı ve sabah ilk basma sırasındaki ağrı değerlendirmesinde sadece silikon tabanlık kullanan kontrol grubuna göre anlamlı fark gözlenmiştir. Topuk dikeni ağrısının sabah ilk basma sırasında ve gün sonunda daha belirgin olduğu göz önüne alındığında, özellikle bu dönemlerde ağrıda azalma olması anlamlıdır. Önceki çalışmalarda farklı cihazlarla çok çeşitli tedavi protokolleri denenmiş olup (31), çalışmamızda cihaz kullanımındaki firma önerileri ve klinik deneyimlerimiz doğrultusunda daha önceki çalışmalara göre daha kısa aralıkla ve daha düşük dozda kullanılmıştır. Bu tedavi protokolü ile ağrı semptomunda iyileşme elde edilebilmiştir.

Fonksiyon üzerine yapılan çalışma sonuçları da genellikle olumlu görülmektedir. Gerdesmeyer L ve ark., ESWT inatçı plantar fasiit mevcut olan hastalarda kontrol grubu ile karşılaştırılmış ağrı, fonksiyon ve yaşam kalitesi üzerine etkili olduğu sonucuna varılmıştır (22). Chew ve ark.'nın yaptığı çalışmada plantar fasitte trombositten zengin plazma ve ESWT'nin VAS ile ölçülen ağrı ve AOFAS ile ölçülen ayak fonksiyonu skorlarında anlamlı düzelme görülmüştür (32). Bizim çalışmamızda grup içi karşılaştırmada her iki grupta da FAOS ile ölçülen ayak fonksiyon değerlendirme skorlarında grup içi analizlerde tedavi sonrasında iyileşme görülmekle beraber, tedavi grubu ile kontrol grubu arasında tedavi sonrasinda anlamlı farklılık saptanmamıştır. Hammer ve ark.'nın yaptı̆̆ı çalışmada bizim çalışmamızın sonuçlarını destekler biçimde ESWT'nin konservatif tedavilere üstünlüğü değerlendirilmiş her iki grupta grup içi değerlendirmelerde ağrı ve fonksiyonda iyileşme gözlenmiş, gruplar arasında herhangi bir farklılık gözlenmemiştir (29). ESWT'nin farklı dozların karşılaştırıldığı çalışmalarda farklı tedavi dozlarında özellikle orta ve uzun dönemde etkinlik farklılıkları ortaya konulmuştur (24, $33)$.

Çalışmalarda kullanılan ESWT dozlarının ve ölçüm metotlarının değişkenliği, çalışmalar arasında birebir karşılaştırma yapmayı engellemektedir. $\mathrm{Bu}$ nedenle çalışmalar arasındaki sonuç farklılıklarının kesin sebebine ulaşmak mümkün değildir. Fakat çalışmalardaki değişken seans sayısı, frekans ve dozajda uygulanan tedavi yöntemlerinin farklı sonuçlar elde edilmesinde etkili olduğu düşünülebilir. Çalışmamız, kontrol grubunun bulunması ve ağrı ile eş zamanlı fonksiyonel değerlendirmesinin yapılması açısından önemlidir. Hasta sayısının kısıtlı olması ve uzun dönem takip sonuçlarının olmaması çalışmamızın limitasyonları arasındadır.

Sonuç olarak, silikon tabanlığa ek olarak uygulanan ESWT tedavisinin sadece silikon tabanlık kullanımına göre hastaların ağrı semptomunu iyileştirmede daha etkin olduğu görülmüştür. Daha fazla hasta sayıs1 ile uzun dönem takipli çalışmaya ihtiyaç bulunmaktadır.

\section{Kaynaklar}

1. Crawford F, Atkins D, Edwards J. Interventions for treating plantar heel pain. Cochrane Database Syst Rev. 2000;(3):CD000416. doi:10.1002/14651858. CD000416

2. Mücke R, Schönekaes K, Micke O, Seegenschmiedt MH, Berning D, Heyder R Low-dose radiotherapy for painful heel spur. Retrospective study of 117 patients. Strahlenther Onkol. 2003;179(11):774-778. doi:10.1007/s00066-003-1126-9

3. Aşansu MA, Yıldırım Y. Topuk ağrısı. TOTBID Dergisi 2013;12:447-454.

4. Hanada M, Takahashi M, Matsuyama Y. The effect of extracorporeal shock wave therapy for the treatment of plantar fasciitis in regard to middle-aged patients' activity level and pain localization. Shock Waves 2019; 29(2):321-326.

5. Hill JJ Jr, Cutting PJ. Heel pain and body weight. Foot Ankle. 1989;9(5):254-256. doi: $10.1177 / 107110078900900509$

6. Özdemir H, Özdemir A, Bilbaşar H, et al. Topuk ağrısında non-invaziv konservatif tedavi sonuçları ve epin kalkaneinin topuk ağrısındaki rolü. J Arthroplasty \& Arthroscop Surg 2002;13(4):247-255

7. Pfeffer GB. Plantar heel pain. Instr Course Lect 2001;50:521-31.

8. Lizis P. Chosen conservative treatments on the symptoms of calcaneal spur: a short review. Int J Foot Ankle 2018;2(1):1-6.

9. Speed CA. Extracorporeal shock-wave therapy in the management of chronic softtissue conditions. J Bone Joint Surg Br. 2004;86(2):165-171. doi:10.1302/0301 $620 \mathrm{x} .86 \mathrm{~b} 2.14253$

10. Buchbinder R, Ptasznik R, Gordon J, Buchanan J, Prabaharan V, Forbes A. Ultrasound-guided extracorporeal shock wave therapy for plantar fasciitis: a randomized controlled trial. JAMA. 2002;288(11):1364-1372. doi:10.1001/ jama.288.11.1364

11. Haake M, Buch M, Schoellner C, et al. Extracorporeal shock wave therapy for plantar fasciitis: randomised controlled multicentre trial. BMJ. 2003;327(7406):75. doi:10.1136/bmj.327.7406.75

12. Yalcin E, Keskin Akca A, Selcuk B, Kurtaran A, Akyuz M. Effects of extracorporal shock wave therapy on symptomatic heel spurs: a correlation between clinical outcome and radiologic changes. Rheumatol Int. 2012;32(2):343-347. doi:10.1007/ s00296-010-1622-Z

13. Moretti B, Garofalo R, Patella V, Sisti GL, Corrado M, Mouhsine E. Extracorporeal shock wave therapy in runners with a symptomatic heel spur. Knee Surg Sports Traumatol Arthrosc. 2006;14(10):1029-1032. doi:10.1007/s00167-005-0025-2

14. Cosentino R, Falsetti P, Manca S, et al. Efficacy of extracorporeal shock wave treatment in calcaneal enthesophytosis. Ann Rheum Dis 2001;60(11):1064-1067.

15. Ogden JA, Alvarez RG, Marlow M. Shockwave therapy for chronic proximal plantar fasciitis: a meta-analysis. Foot Ankle Int. 2002;23(4):301-308. doi: $10.1177 / 107110070202300402$

16. Kane RL, Bershadsky B, Rockwood T, Saleh K, Islam NC. Vi- sual Analog Scale pain reporting was standardized. J Clin Epidemiol 2005;58(6):618-23.

17. Roos E.B.S., Karlsson, J. Validation of the foot and ankle out-come score for ankle ligament reconstruction. Foot and Ankle International. 2001;22(10):788-94.

18. Karatepe AG, Günaydin R, Kaya T, Karlibaş U, Özbek G. Validation of the Turkish version of the foot and ankle outcome score. Rheumatol Int. 2009;30(2):169-173. doi:10.1007/s00296-009-0929-0

19. Rompe JD, Hopf C, Nafe B, Burger R. Low-energy extracorporeal shock wave therapy for painful heel: a prospective controlled single-blind study. Arch Orthop Trauma Surg. 1996;115(2):75-79. doi:10.1007/BF00573445

20. Aqil A, Siddiqui MR, Solan M, Redfern DJ, Gulati V, Cobb JP. Extracorporeal shock wave therapy is effective in treating chronic plantar fasciitis: a meta-analysis of RCTs. Clin Orthop Relat Res. 2013;471(11):3645-3652. doi:10.1007/s11999013-3132-2

21. Wirtz DC, Heller KD, Niethard FU. Biomechanical aspects of load-bearing capacity after total endoprosthesis replacement of the hip joint. An evaluation of current knowledge and review of the literature. Z Orthop Ihre Grenzgeb. 1998;136(4):310316. doi:10.1055/s-2008-1053743

22. Gerdesmeyer L, Frey C, Vester J, et al. Radial extracorporeal shock wave therapy is safe and effective in the treatment of chronic recalcitrant plantar fasciitis: results of a confirmatory randomized placebo-controlled multicenter study. Am J Sports Med 2008;36(11):2100-2109. doi:10.1177/0363546508324176

23. Tuna S. Plantar fasiitli hastalarda ekstrakorporeal şok dalga tedavisi. Dicle Med J 41(2):2:337-40. doi: 10.5798/diclemedj.0921.2014.02.0427

24. Küçükakkaş O, Öz B, Koçyiğit H. Efficacy of different doses of radial extracorporeal shock therapy in patients with painful calcaneal spur. Turk J Phys Med Rehab 2017;63(1):31-41.

25. Hayta E, Salk I, Gumus C, Tuncay MS, Cetin A. Extracorporeal shock-wave therapy effectively reduces calcaneal spur length and spur-related pain in overweight and obese patients. J Back Musculoskelet Rehabil. 2016; doi:10.3233/BMR-160708.

26. Cağlar Okur S, Aydın A. Comparison of extracorporeal shock wave therapy with custom foot orthotics in plantar fasciitis treatment: A prospective randomized oneyear follow-up study. J Musculoskelet Neuronal Interact. 2019;19(2):178-186

27. Uğurlar M, Sönmez MM, Uğurlar ÖY, Adıyeke L, Yıldırım H, Eren OT. Effectiveness of Four Different Treatment Modalities in the Treatment of Chronic Plantar Fasciitis During a 36-Month Follow-Up Period: A Randomized Controlled Trial. J Foot Ankle Surg. 2018;57(5):913-918. doi:10.1053/j.jfas.2018.03.017

28. Wang CJ, Wang FS, Yang KD, Weng LH, Ko JY. Long-term results of extracorporeal shockwave treatment for plantar fasciitis. Am J Sports Med. 2006;34(4):592-596. doi: $10.1177 / 0363546505281811$ 
29. Hammer DS, Adam F, Kreutz A, Kohn D, Seil R. Extracorporeal shock wave therapy (ESWT) in patients with chronic proximal plantar fasciitis: a 2-year followup. Foot Ankle Int. 2003;24(11):823-828. doi:10.1177/107110070302401103

30. Metzner G, Dohnalek C, Aigner E. High-energy Extracorporeal Shock-Wave Therapy (ESWT) for the treatment of chronic plantar fasciitis. Foot Ankle Int. 2010;31(9):790-796. doi:10.3113/FAI.2010.0790

31. Li X, Zhang L, Gu S, et al. Comparative effectiveness of extracorporeal shock wave, ultrasound, low-level laser therapy, noninvasive interactive neurostimulation, and pulsed radiofrequency treatment for treating plantar fasciitis: A systematic review and network meta-analysis. Medicine (Baltimore). 2018;97(43):e12819. doi:10.1097/MD.0000000000012819

32. Chew KT, Leong D, Lin CY, Lim KK, Tan B. Comparison of autologous conditioned plasma injection, extracorporeal shockwave therapy, and conventional treatment for plantar fasciitis: a randomized trial. PM R. 2013;5(12):1035-1043. doi:10.1016/j.pmrj.2013.08.590

33. Chow IH, Cheing GL. Comparison of different energy densities of extracorporea shock wave therapy (ESWT) for the management of chronic heel pain. Clin Rehabil. 2007;21(2):131-141. doi:10.1177/0269215506069244 